\title{
Addendum
}

Obere Extremität 2018 $\cdot 13: 65$

https://doi.org/10.1007/s11678-017-0436-y

Online publiziert: 20. November 2017

(c) Springer Medizin Verlag $\mathrm{GmbH}$, ein Teil von Springer Nature 2017

CrossMark

J. Schmalzl (D) - L. J. Lehmann

Abteilung für Unfall- und Handchirurgie, St. Vincentius Klinik, Karlsruhe, Deutschland

\section{Addendum zu: Die arthroskopisch assistierte Osteosynthese von Radiuskopffrakturen}

\author{
Addendum zu: \\ Obere Extremität 2017 \\ https://doi.org/10.1007/s11678-017- \\ 0427-z
}

Acknowledgement. Das Video „Arthroscopic osteosynthesis of radial head fractures" $\mathrm{zu}$ dieser Publikation wurde von der Deutschen Vereinigung für Schulter- und Ellenbogenchirurgie (DVSE) e. V. mit dem Alwin Jäger Videopreis 2017 ausgezeichnet.

\section{Korrespondenzadresse}

Dr. med. J. Schmalzl

Abteilung für Unfall- und Handchirurgie,

St. Vincentius Klinik

Südendstraße 32, 76137 Karlsruhe,

Deutschland

jonas.schmalzl@vincentius-ka.de 